\title{
Enfermedad de Ménétrier en pacientes pediátricos secundaria a una infección por citomegalovirus. Presentación de dos casos clínicos en un centro de alta complejidad
}

\author{
Ménétrier's disease in pediatric patients secondary to cytomegalovirus infection. \\ Presentation of two clinical cases in a high complexity center
}

\author{
Dr. Gustavo Tagliaferro ${ }^{a}$, Dr. Julián Llera ${ }^{a}$ y Dra. Marina Orsia
}

\begin{abstract}
RESUMEN
La enfermedad deMénétrier es una gastroenteropatía perdedora de proteínas. Definida como una entidad rara y de causa desconocida, la mayoría de los casos reportados la han asociado a infecciones virales. En los pacientes pediátricos, presenta un comienzo agudo con un curso benigno y autolimitado.

Se caracteriza por tener pliegues gástricos engrosados que, generalmente, involucran el cuerpo y el fundus gástrico, asociados a hipoalbuminemia, debido a la pérdida de proteína sérica a través de la mucosa. A continuación, se exponen dos casos clínicos de síndrome de Ménétrier infantil asociado a infección por citomegalovirus.

Palabras clave: enfermedad de Ménétrier, enteropatía perdedora de proteinas, citomegalovirus, gastropatía hipertrófica.
\end{abstract}

\begin{abstract}
Ménétrier's disease is a protein losing gastroenteropathy. Defined as a rare entity with an unknown cause, most of the reported cases have been associated with viral infections. In pediatric patients, it is characterized by an acute onset with a benign and self-limiting course.

It is characterized by thickened gastric folds that generally involve the body and the gastric fundus, associated with hypoalbuminemia due to the loss of serum protein through the mucosa. The following are two clinical cases of infant Ménétrier syndrome associated with cytomegalovirus infection.

Key words: Ménétrier disease, enteropathy, cytomegalovirus, hypertrophic gastropathy.
\end{abstract}

http:/ / dx.doi.org/10.5546/ aap.2019.e158

Cómo citar: Tagliaferro G, Llera J, Orsi M. Enfermedad de Ménétrier en pacientes pediátricos secundaria a una infección por citomegalovirus. Presentación de dos casos clínicos en un centro de alta complejidad. Arch Argent Pediatr 2019;117(2):e158-e162.

a. Hospital Italiano de Buenos Aires.

Correspondencia:

Dr. Gustavo Tagliaferro:

gustavo.tagliaferro@hospitalitaliano.org.ar

Financiamiento: Ninguno.

Conflicto de intereses: Ninguno que declarar.

Recibido: 8-5-2018

Aceptado: 29-11-2018

\section{INTRODUCCIÓN}

La enfermedad de Ménétrier (EM) es una entidad clínica rara, caracterizada por hiperplasia foveolar gástrica, que produce una gastroenteropatía perdedora de proteínas. Se cuentan con varios reportes en adultos, pero pocos en edades pediátricas. ${ }^{1}$

En la población infantil, afecta, habitualmente, a menores de 6 años. Presenta un comienzo agudo, de curso benigno y de carácter autolimitado. ${ }^{2}$ La etiología no es del todo clara; en los niños, se ha relacionado con procesos infecciosos, que incluyen el citomegalovirus, Helicobacter pylori, Mycoplasma o infección por herpes simplex. ${ }^{3}$ Los síntomas iniciales son inespecíficos, similares a cualquier cuadro viral, con fatiga, pérdida de peso, vómitos y/o dolor abdominal. Posteriormente, desarrollan hipoproteinemia e hipoalbuminemia, que puede llegar a una situación de anasarca, con ascitis, derrame pleural y pericárdico. La tríada clásica descrita son los síntomas gastrointestinales, el edema periférico y los pliegues gástricos engrosados. ${ }^{4,5}$ Diferentes estudios, como la seriada esófago-gastroduodenal (SEGD) y la endoscopía, pueden demostrar inflamación de la mucosa y engrosamiento de los pliegues gástricos. ${ }^{6}$ La histología incluye hiperplasia foveolar con dilatación quística, acompañada de atrofia glandular en el cuerpo gástrico. ${ }^{7}$

No existe un tratamiento bien establecido para esta enfermedad. Se han utilizado tratamientos empíricos con antiácidos, anticolinérgicos y prednisona; sin embargo, no existen evidencias sólidas de beneficios asociados a estas terapias. Generalmente, la sintomatología se resuelve en 4-6 semanas, a diferencia de la del adulto, la cual es más grave y con tendencia a la cronicidad. ${ }^{8}$

A continuación, se presentan dos casos clínicos de pacientes internados durante el año 2017 en el Hospital Italiano de Buenos Aires. Uno es un lactante de 11 meses de vida y el otro es un niño de 4 años, ambos con confirmación de 
citomegalovirus tanto por serologías como en las muestras de las biopsias endoscópicas de la mucosa gástrica.

\section{CASO CLÍNICO UNO}

Paciente de 11 meses de vida, derivado de otra institución con diagnóstico de síndrome ascítico edematoso. Una semana antes, comenzó con diarrea y vómitos, y se agregó un edema bipalpebral y en los miembros inferiores. Permaneció internado durante 48 horas, cuando se constató hipoalbuminemia e hiponatremia por análisis de laboratorio y orina normal, y se decidió su traslado a nuestra Institución.

Como antecedentes personales, se trataba de un lactante recién nacido de término, con peso adecuado. Refería un brote generalizado en la piel a los 7 meses de vida, luego de recibir amoxicilina, como único antecedente relevante.

Examen físico: niño en estado de vigilia y reactivo, que respiraba aire del ambiente. Se constató un edema generalizado con un abdomen globuloso y distendido, sin hepatoesplenomegalia. Peso de 10,800 kg, para un referido de $8,900 \mathrm{~kg}$. Signos vitales: frecuencia cardíaca (FC) de 110 por minuto; frecuencia respiratoria (FR): 28 por minuto; saturación arterial de oxígeno (SAT) del $99 \%$ respirando aire ambiental (AA); tensión arterial (TA): $92 / 72$ (80) $\mathrm{mmHg}$; temperatura: $36,6^{\circ} \mathrm{C}$. El resto del examen, sin particularidades.
Se internó en la Sala de Pediatría y presentó un análisis de laboratorio inicial con glóbulos blancos (GB): $16800 / \mathrm{mm}^{3}$ (fórmula: el $46 \%$ de neutrófilos, el $41 \%$ de linfocitos, el $10 \%$ de monocitos, el 2,6\% de eosinófilos); proteína $C$ reactiva (PCR): $20 \mathrm{mg} / \mathrm{L}$ (valor normal -VN-: < 5); sodio: 132 $\mathrm{mEq} / \mathrm{L}$ (VN: 135-145); proteínas totales: $2,9 \mathrm{~g} / \mathrm{dl}$; y albúmina: 1,7 g/ dl (VN: 3-3,5); triglicéridos: 195 $\mathrm{mg} / \mathrm{dl}(\mathrm{VN}:<150)$. Hepatograma y función renal, dentro de los parámetros normales; orina normal sin proteinuria. Carga viral del virus de EpsteinBarr (VEB) negativa y de citomegalovirus positiva (815 copias). Telerradiografía de tórax y ecografía abdominal normales; cultivos en materia fecal (gérmenes típicos y atípicos) negativos.

Se indicó balance estricto, restricción hídrica, pasaje de albúmina y furosemida, y controlar diariamente el peso y la TA. Se descartaron otras etiologías, como la cardiovascular, la renal o la hepática.

Se consultó con el Servicio de Gastroenterología Infantil y se solicitaron anticuerpos por la sospecha de crisis celíaca, los cuales fueron negativos, clearance de alfa1-antitripsina de $13 \mathrm{~g} / 24 \mathrm{~h}(\mathrm{VN}:<12,5)$ y calprotectina en materia fecal $>1000 \mu \mathrm{g} / \mathrm{g}(\mathrm{VN}$ : $<500$ ).

La SEGD reveló defecto en el llenado en la pared gástrica, con predominio del fundus, compatible con hipertrofia de pliegues gástricos (Figura 1). Ante la sospecha de enteropatía

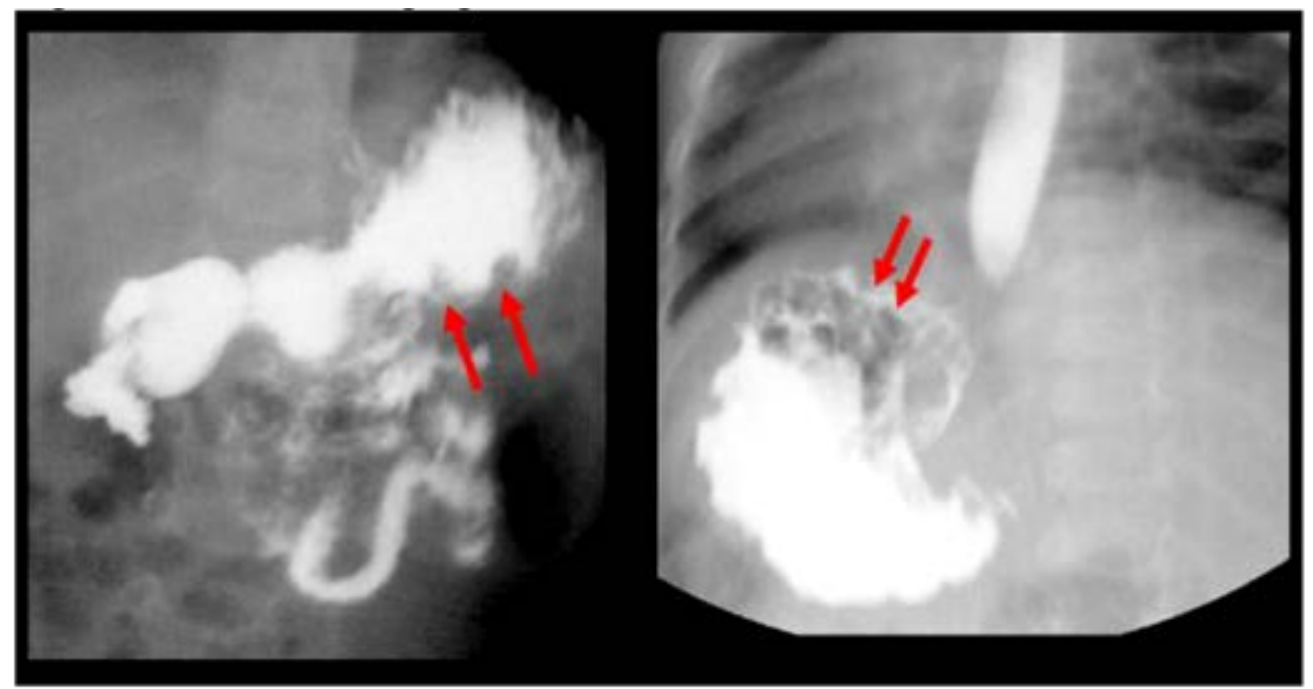

Seriada esófago-gastroduodenal donde se observan defectos de relleno en la pared gástrica, en el fondo y en el cuerpo del estómago, compatibles con hipertrofia de pliegues gástricos. Autora: Dra. Kreindel, Tamara. 
perdedora de proteínas, se realizó una videoendoscopía digestiva alta (VEDA) con toma de biopsias. Se observó nodularidad en toda la mucosa gástrica con predominio del cuerpo y del fundus, y presencia de pliegues engrosados. La anatomía patológica informó mucosa con hiperplasia foveolar, lámina propia con edema rica en eosinófilos y aisladas células fúndicas con citomegalia, sugestiva de efecto citopático por citomegalovirus. El ácido desoxirribonucleico $(\mathrm{ADN})$ para citomegalovirus fue detectable en la muestra endoscópica (Figura 2).
El sexto día de internación, el paciente superó la diarrea, con edema localizado a nivel bipalpebral, sin requerimiento de pasaje de albúmina. Con diagnóstico de síndrome de Ménétrier secundario a citomegalovirus, se decidió comenzar con inhibidor de bomba de protones (IBP) a razón de $1 \mathrm{mg} / \mathrm{kg} /$ día y valganciclovir a razón de $20 \mathrm{mg} / \mathrm{kg} /$ día.

El paciente permaneció internado un total de nueve días y egresó con un peso de 9,500 $\mathrm{kg}$, sin presentar edemas ni diarrea (Figura 3). Con un análisis de laboratorio con GB: 13000 /

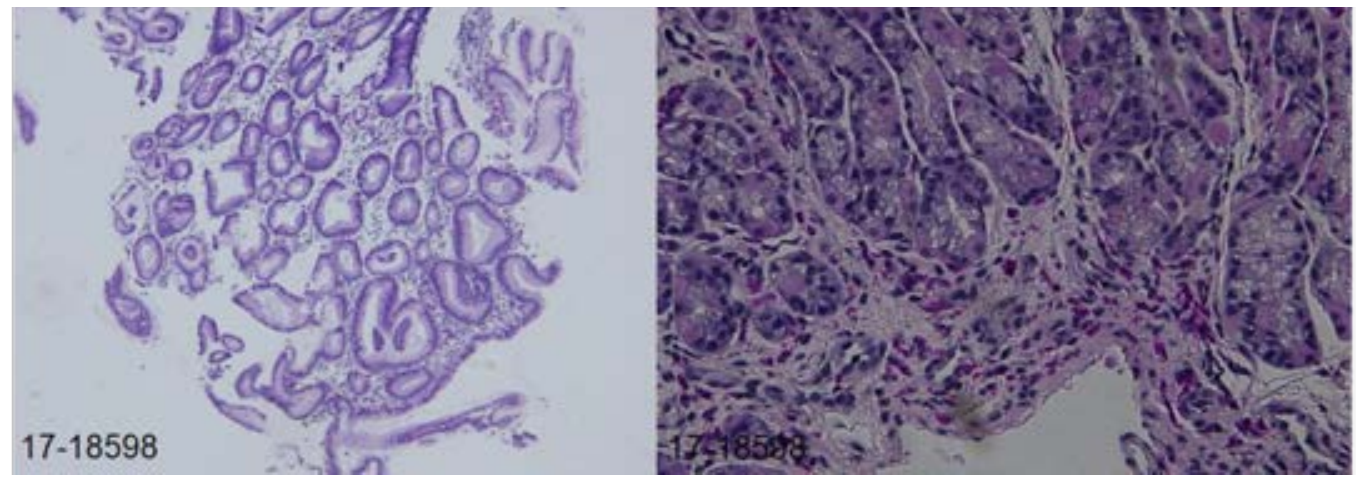

Mucosa gástrica con edema en lámina propia y marcada hiperplasia foveolar (izquierda). Mucosa gástrica oxíntica con numerosos eosinófilos característicos de la enfermedad (derecha). Autora: Dra. De la Iglesia, Paola.

FIGURA 3. Gráfico de los valores de albúmina y gammaglobulina durante el primer mes de seguimiento clínico

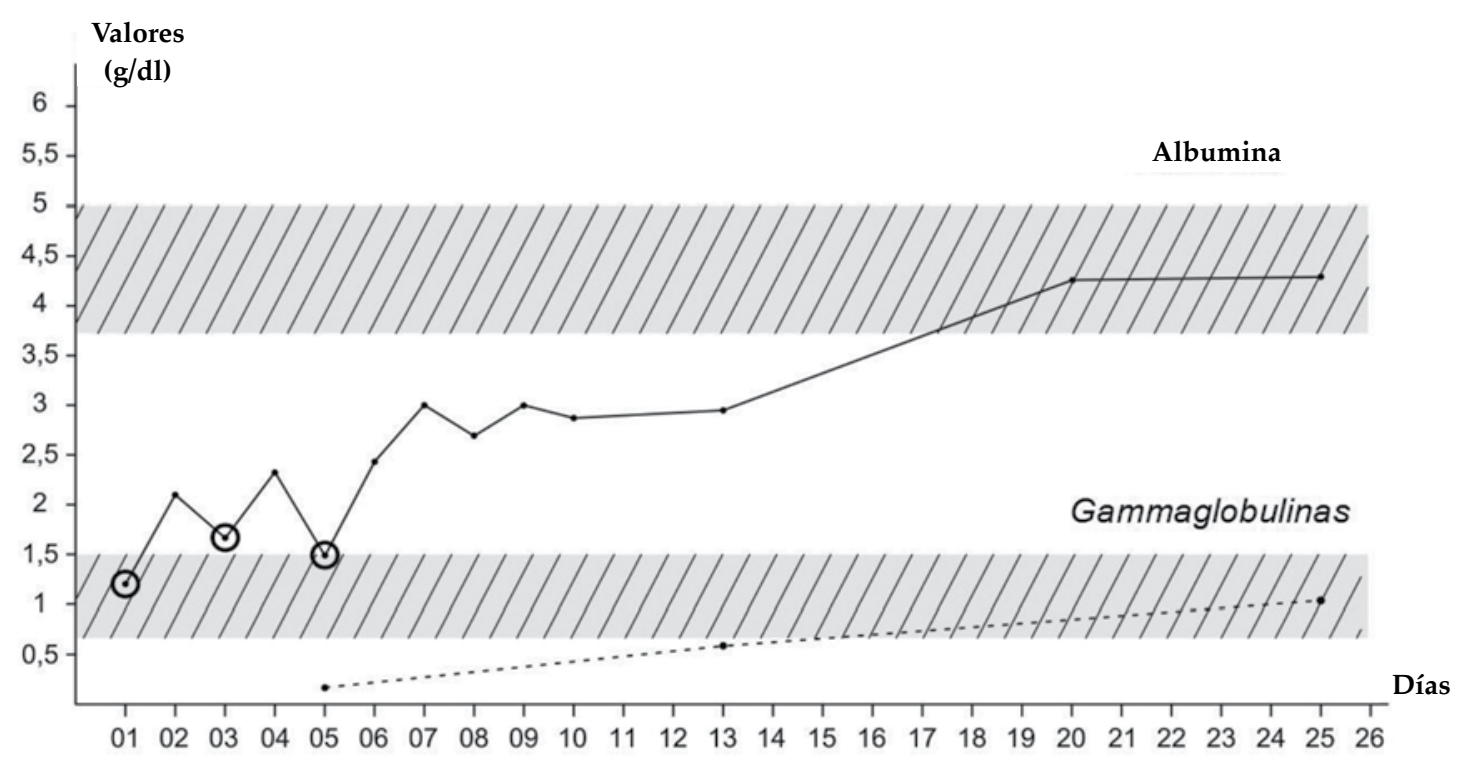

Requerimiento de albúmina endovenosa durante los primeros días de internación (en tres oportunidades); se estabilizó entre los días 9 y 13. Se observa como se normaliza a partir de la tercera semana. 
$\mathrm{mm}^{3}$; proteínas: $4,6 \mathrm{~g} / \mathrm{dl}$; albúmina: $2,86 \mathrm{~g} / \mathrm{dl}$; ionograma: $141-5,2-113 \mathrm{mEq} / \mathrm{L}$; triglicéridos: $330 \mathrm{mg} / \mathrm{dl}$; y cargas virales de citomegalovirus menores de 150. Dieta hiposódica, leche parcialmente hidrolizada, IBP y valganciclovir (este último, durante siete días). Presentó niveles en ascenso de albúmina sérica y cargas virales negativas a la semana de su egreso.

\section{CASO CLÍNICO DOS}

Paciente de 4 años de edad, previamente sano, que ingresó por la Guardia, por presentar fiebre y vómitos de 24 horas de evolución. Del interrogatorio surgió que los padres habían padecido infección por citomegalovirus (un mes atrás), por lo que se realizaron serologías al paciente, que fueron VEB (inmunoglobulina $\mathrm{M}-\operatorname{Ig} \mathrm{M}-+)$, citomegalovirus ( $\operatorname{Ig} \mathrm{M}+$, inmunoglobulina $\mathrm{G}-\operatorname{Ig} \mathrm{G}-+)$. A las 48 horas, consultó nuevamente por agregarse distensión abdominal con edema de ambos párpados.

Al momento del examen físico, presentaba abdomen marcadamente distendido, matidez ante la percusión, diuresis y catarsis conservada. Peso de 20,200 kg, referido de 19,500 kg. En cuanto a los signos vitales, FC: 119; FR: 26; SAT.: $98 \%$ (AA); temperatura: $36,9^{\circ} \mathrm{C}$; TA: $105 / 66$ (72) mmHg.

Análisis de laboratorio inicial con GB: 21185/ $\mathrm{mm}^{3}$ (fórmula: el $62 \%$ de linfocitos, el $25 \%$ de neutrófilos, el $10 \%$ de monocitos, el 1,2\% de eosinófilos); proteínas: 3,3 g/ dl (VN: 6,37,8); albúmina: $1,7 \mathrm{~g} / \mathrm{dl}$ (VN: 3-3,5); urea: 48 $\mathrm{mg} / \mathrm{dl}$ (VN: 11-39); creatinina: $0,39 \mathrm{mg} / \mathrm{dl}$; sodio: $128 \mathrm{mEq} / \mathrm{L}$ (VN: 135-145). Hepatograma normal, orina completa normal, sin proteinuria. Se realizó una ecografía abdominal y se observó esplenomegalia homogénea (105 mm), líquido libre moderado perihepático, derrame pleural bilateral leve (de $15 \mathrm{~mm}$ el derecho y de $4 \mathrm{~mm}$ el izquierdo).

Ingresó a la Sala de Pediatría, en donde recibió corrección con albúmina del $20 \%$. Se solicitaron cargas virales para VEB no detectables y de citomegalovirus positivas (214 copias). Anticuerpos para enfermedad celíaca, negativos.

Por la sospecha de enteropatía posviral, se solicitaron estudios por imágenes, SEGD (la cual no se pudo realizar por falta de colaboración del paciente) y ecografía abdominal, y se constató el engrosamiento de los pliegues gástricos.

Se interconsultó con el Servicio de Gastroenterología Infantil, que realizó una endoscopía digestiva con toma de biopsias. Se observó techo gástrico nodular, pliegues gástricos engrosados con edema y microhemorragias aisladas (Figura 4). Se inició el tratamiento con $1 \mathrm{mg} / \mathrm{kg} /$ día de IBP y $5 \mathrm{ml}$ de sucralfato (cada $12 \mathrm{~h}$ ), asumiendo el cuadro como enfermedad de Ménétrier. La biopsia del estómago informó mucosa antral y corpofúndica con edema e incremento de eosinófilos. Citomegalovirus detectable por PCR en la muestra de la biopsia.

El paciente permaneció internado cuatro días y evolucionó favorablemente. El análisis de laboratorio al egresar fue GB: $15076 / \mathrm{mm}^{3}$ (fórmula: el $47 \%$ de linfocitos, el $40 \%$ de neutrófilos, el 10,39\% de monocitos, el 1,9\% de eosinófilos); urea: $29 \mathrm{mg} / \mathrm{dl}$; creatinina: 0,33 $\mathrm{mg} / \mathrm{dl}$; sodio: $145 \mathrm{mEq} / \mathrm{L}$; proteínas: 3,75 g/ dl; albúmina: 2,47 g/dl; clearance de alfa-1antitripsina: $12,1 \mathrm{~g} / 24 \mathrm{~h}(\mathrm{VN}:<12,5)$.

Se realizó el seguimiento ambulatorio en tratamiento con IBP y sucralfato durante 4 semanas totales.
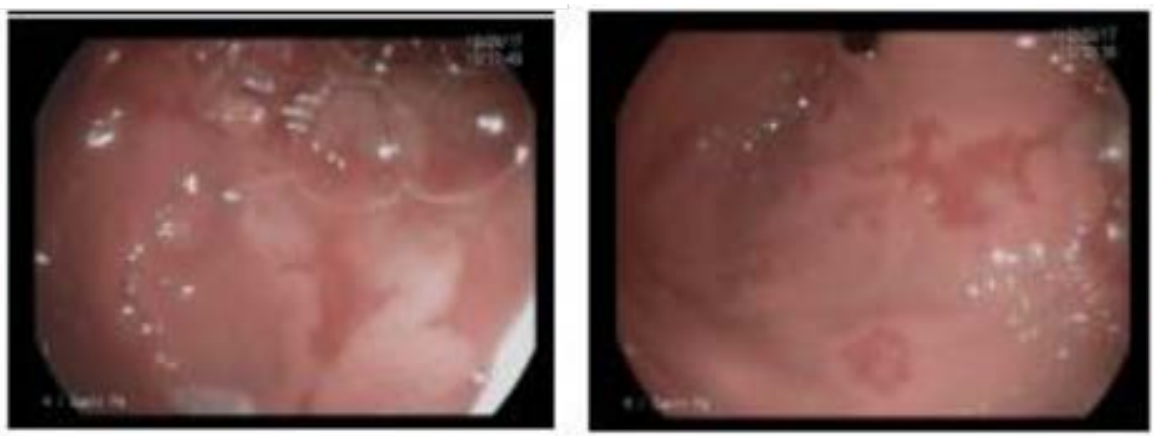

Se observa edema y microhemorragias en el techo y en el cuerpo gástrico. Pliegues engrosados. 


\section{DISCUSIÓN}

La EM, descrita por primera vez por el patólogo francés Pierre Ménétrier en 1888, se caracteriza por pliegues hipertróficos en el cuerpo del estómago, hiperplasia foveolar e hipoproteinemia.

La bibliografía describe el H. pylori y el citomegalovirus como los dos microorganismos más frecuentes a la hora de producir EM, y se rescata este último en un tercio de los pacientes pediátricos.

La fisiopatología de la enfermedad y los efectos del citomegalovirus en la manifestación clínica no han sido claramente dilucidados. Se sugiere que el virus interviene en la sobreexpresión del factor de crecimiento transformante- $\alpha$ (transforming growth factor alpha; TGF $\alpha$, por sus siglas en inglés). De esta manera, se estimula la proliferación de células productoras de mucina y, además, se ampliarían las uniones entre las células epiteliales gástricas, lo que conduciría a una pérdida proteica en el tracto gastrointestinal.

Se caracteriza por tener una presentación aguda, con posterior remisión espontánea en el trascurso de 4 a 6 semanas, comportamiento que se pudo observar en ambos pacientes.

Esto la diferencia de los casos reportados en los adultos, en los que puede aumentar el riesgo de cáncer gástrico y requerirse, en varias oportunidades, gastrectomías parciales como manejo terapéutico de la enfermedad.

El diagnóstico diferencial para considerar en estas enteropatías incluye la enfermedad celíaca, la gastroenteritis eosinofílica y el linfoma gástrico, entre otras. Por lo tanto, se recomienda la interconsulta al especialista y la endoscopía digestiva de manera oportuna, que es una herramienta útil para evaluar las características de los pliegues, que apoya el diagnóstico de EM, y realizar la toma de la biopsia para el eventual rescate de germen.

No existe, a la fecha, un tratamiento bien establecido para estos pacientes. Se han utilizado terapias empíricas con antiácidos, anticolinérgicos y octreotrida. Sin embargo, no existen evidencias claras de estos beneficios según lo reportado por la bibliografía. ${ }^{9}$ Así mismo, un artículo publicado por el World Journal of Gastroenterology describe la falta de remisión en un paciente de 4 años de edad, que, al evolucionar a la cronicidad, presentó una respuesta favorable con el uso de octreotrida. ${ }^{2}$ Además, cuando la enfermedad es secundaria a citomegalovirus, el efecto con valganciclovir sigue siendo controvertido por el curso autolimitado de su presentación, por lo que puede considerarse en aquellas con un curso prolongado. ${ }^{10}$

La importancia radica en el soporte terapéutico de estos pacientes, así como en su manejo sintomático, que incluye una hidratación adecuada, agentes antisecretores (antagonistas del receptor de histamina H2 e IBP) y pasaje de albúmina endovenosa.

En conclusión, se presentaron dos casos clínicos sobre una patología poco común, ambos con una presentación clínica similar y característica. Se recomienda sospecharla en todo niño que presente edema, hipoalbuminemia sin proteinuria, sin disfunción hepática, junto con pliegues gástricos engrosados en los estudios por imágenes.

\section{Agradecimientos}

Dra. Paola De la Iglesia y Dra. Tamara Kreindel en su aporte a la recolección de datos y la descripción de imágenes.

\section{REFERENCIAS}

1. Kirberg BA, Rodríguez BV, Donoso VF, Kirhmant T, et al. Gastropatía hipertrófica perdedora de proteínas: Enfermedad de Ménétrier. Caso clínico. Rev Chil Pediatr. 2014; 85(1):80-5.

2. Di Nardo G, Oliva S, Aloi M, Frediani S, et al. A pediatric non-protein losing Menetrier's disease successfully treated with octreotide long acting release. World J Gastroenterol. 2012; 18(21):2727-9.

3. Velmishi V, Elezi B, Cekodhima G. Menetrier Disease in a Five Year Old Girl - A Case Report and Review of Literature. J Gastrointest Dig Syst. 2016; 06:395.

4. Ding Q, Lu P, Ding S, Fan Y, et al. Ménétrier disease manifested by polyposis and involved in both the small bowel and entire colon: A Case Report. Medicine (Baltimore). 2016; 95(36):e4685.

5. Akita C, Saikawa Y. Gastric Gyri - Pediatric Ménétrier's Disease. N Engl J Med. 2017; 376(8):774.

6. Hong J, Lee S, Shon Y. Ménétrier's Disease as a Gastrointestinal Manifestation of Active Cytomegalovirus Infection in a 22-Month-Old Boy: A Case Report with a Review of the Literature of Korean Pediatric Cases. Clin Endosc. 2018; 51(1):89-94.

7. Konstantinidou AE, Morphopoulos G, Korkolopoulou P, Eftychiadis C, et al. Menetrier disease of early infancy: a separate entity? J Pediatr Gastroenterol Nutr. 2004;39(2):177-82.

8. Bancila I, Popescu I, Herlea V, Becheanu G, etal. Ménétrier's disease: a rare entity which mimicks gastric cancer. $J$ Gastrointestin Liver Dis. 2016; 25(2):137.

9. Gompertz M, Montenegro C, Bufadel ME, DefilippiC, et al. Enfermedad de Ménétrier con compromiso gástrico difuso y duodenal: Caso clínico. Rev Méd Chile. 2012; 140:1174-8.

10. Hoffer V, Finkelstein Y, Balter J, Feinmesser M, et al. Ganciclovir treatment in Ménétrier's disease. Acta Paediatr. 2007;_92(8):983-5. 